\title{
'SOJA, ZO ALS DIE UIT OOST-INDIEN KOMT': DE VROEGE GESCHIEDENIS VAN SOJASAUS IN NEDERLAND
}

\section{Smaakversterkers in de keuken: olie- en azijnstelletjes}

Hoewel we nooit zullen weten hoe een $17^{\mathrm{e}}$-eeuwse maaltijd precies smaakte, wijzen zowel details in de schilderkunst als in de materiële kunst er op dat men met enige regelmaat zout, azijn, en olie toevoegde aan gerechten. Op een aanzienlijk aantal Nederlandse $17^{\mathrm{e}}$-eeuwse stillevens staat bijvoorbeeld een glazen fles of kan voor azijn, zoals op het bekende Stilleven met vergulde bokaal van Willem Claesz. Heda uit 1635 (afb. 1). Een elegant glazen kannetje staat naast een zilveren zoutvat. Naast zulke fijne glazen karafjes voor olie en azijn waren in de $17^{\mathrm{e}}$ en $18^{\mathrm{e}}$ eeuw ook zilveren en geglazuurde olie- en azijnstelletjes populair. Het in Delft gemaakte olie- en azijnstel in afbeelding 2, bijvoorbeeld, stamt uit het eerste kwart van de $18^{e}$ eeuw.

In de verzameling Aziatische keramiek van de Jan Menze van Diepen U. Stichting in Slochteren bevindt zich ook een olie- en azijnstel. ${ }^{1}$ Het gaat om een $18^{\mathrm{e}}$-eeuwse in Japan vervaardigde olie- en azijnset (afb. 3). In het midden van het ronde plateau met platte rand rijst een holle stam op, met daaromheen zes standringen versierd met een gouden randje. De ringen dienen om de vijf schenkkannetjes en het zoutvat op hun plaats te houden. De vorm van dit zoutvat is vergelijkbaar met het zoutvat op Claesz' schildering. De schenkkannetjes met vergulde A-vormige tuit en een C-vormig handvat zijn versierd met patronen van bloemen en planten. Op ieder kannetje zien we een blauwe cirkel met daarin een gouden letter A, O of S. Het gaat hier duidelijk om een pronkstuk voor de eettafel. ${ }^{2}$ Hoewel de set voornamelijk voor de sier bedoeld was, geven de letters op de kannetjes toch een specifieke betekenis voor gebruik aan: de O staat voor olie en de A voor azijn.

Een vergelijkbare olie- en azijnset uit de collectie van het Princessehof (afb. 4) oogt net iets anders dan het Jan Menze van Diepen exemplaar, met meer gekrulde handvaten en drakenkopjes aan ieder tuitje, en kent een andere samenstelling (geen zoutvat). Het Ashmolean Museum in Oxford heeft ook een aantal vergelijkbare objecten, zoals de set van twee porseleinen flesjes. Deze flesjes, met rood-roze email en goudkleurig gedecoreerd, zijn bedekt met pioenrozen en bladeren, en tonen in een cirkelvormig medaillon respectievelijk de letter 'A' en 'S'.

In de collectie van het Ashmolean Museum bevindt zich ook een plateau met kannetjes en een zoutvat van veel kleinere afmetingen dan het Van Diepen exemplaar. Het gaat om een plateau met een doorsnede van bijna de helft van het Van Diepen plateau, terwijl de kannetjes maar één centimeter lager zijn. (Het Ashmolean noemt het een miniatuur.) De samenstelling is weer iets anders: er is ditmaal een zoutvat, twee olieflesies, een azijnflesje eqn $_{2023}$ 02:58:23Am 
Afb. 1

Stilleven met

vergulde bokaal van

Willem Claesz. Heda (detail), olieverf op

paneel, $88 \times 113 \mathrm{~cm}$., 1635, Rijksmuseum Amsterdam, inv.nr. SK-A-4830

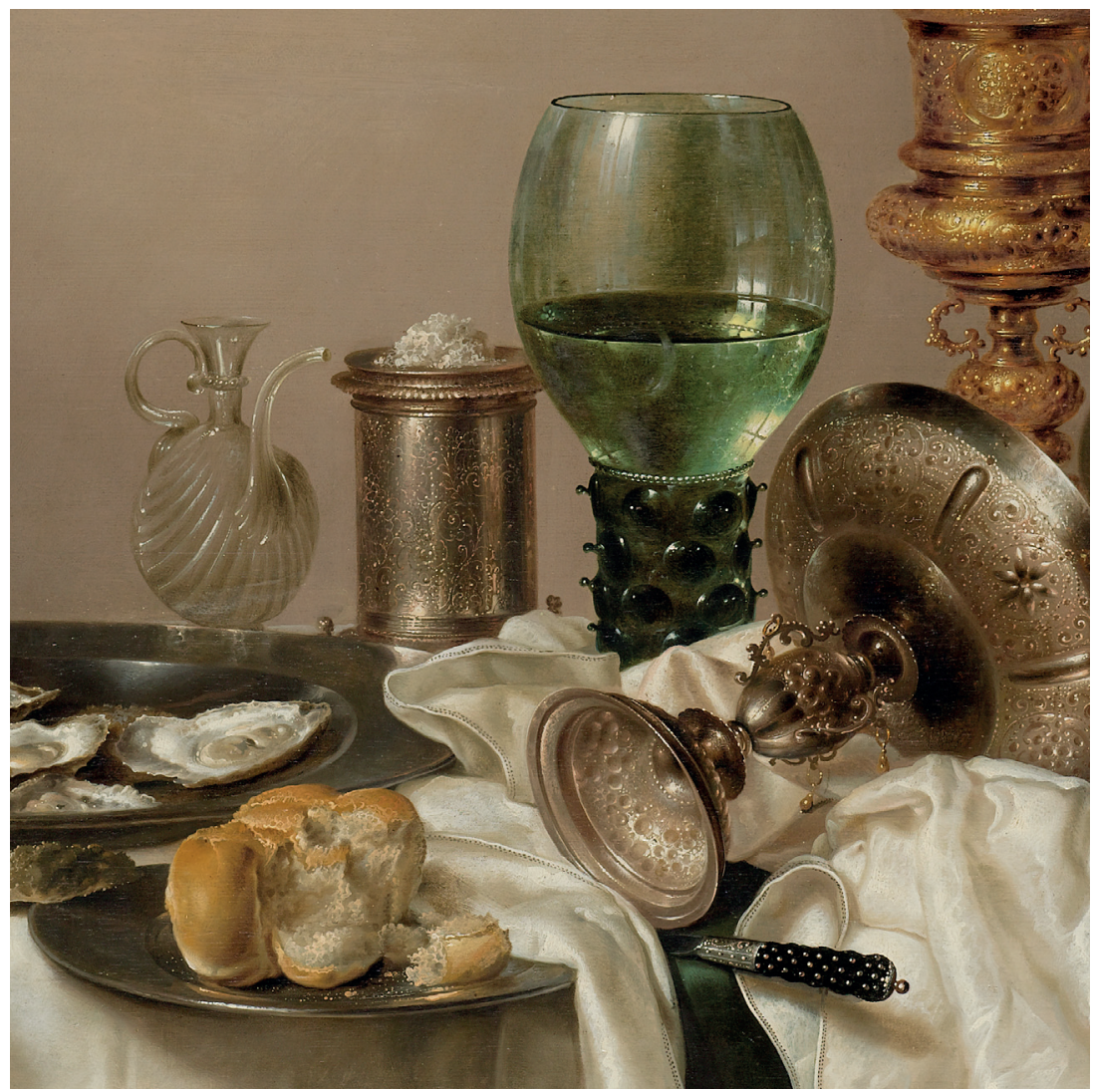

een mosterdpotje (herkenbaar aan de inkeping in de rand voor een lepeltje). Van een vergelijkbaar exemplaar uit de verzameling van Augustus de Sterke in Dresden weten we dat het in 1721 werd verworven. ${ }^{3}$ In het Groninger Museum bevindt zich een soortgelijk Imari miniatuursetje, bestaande uit een mosterdpotje met deksel, een po, een kwispedoor en een zoutvat. ${ }^{4}$

Het bijzondere aan het plateau uit de Jan Menze van Diepen collectie (afb. 3) is dat daarop niet alleen olie- en azijnkannetjes en een zoutvat staan, maar ook twee kannetjes met een S. Het gaat hier om sojaflesjes; blijkbaar werd aan de $18^{\mathrm{e}}$-eeuwse tafel niet alleen zout, azijn en olie geserveerd, maar ook sojasaus. Hoe moeten we dat verklaren? Werd er inderdaad in Nederland zo vroeg al sojasaus gebruikt?

\section{Sojasaus: een eerste kennismaking in Azië}

In 1632 werd aan het Rapenburg in Leiden Aernout van Overbeke (1632-74) geboren (afb 6). In 1643 startte hij zijn studie rechten aan de universiteit in Leiden. Vanaf 1659 werkte hij als advocaat voor het Hof van Holland. Hij lijkt echter weinig aandacht voor zijn vak gehad te hebben; de jaren 60 van de $17^{\mathrm{e}}$ eeuw werden door Van Overbeke voornamelijk besteed aan drank en het publiceren van geestige gedichten en toneelstukken. In 1668 trad hij in dienst bij de Vereenigde Oostindische Compagnie. Hij reisde op de Zuidpolsbroek naar Azië, en tussen 1668 en 1672 werkte hij in Batavia als

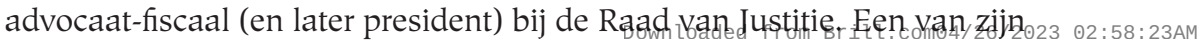




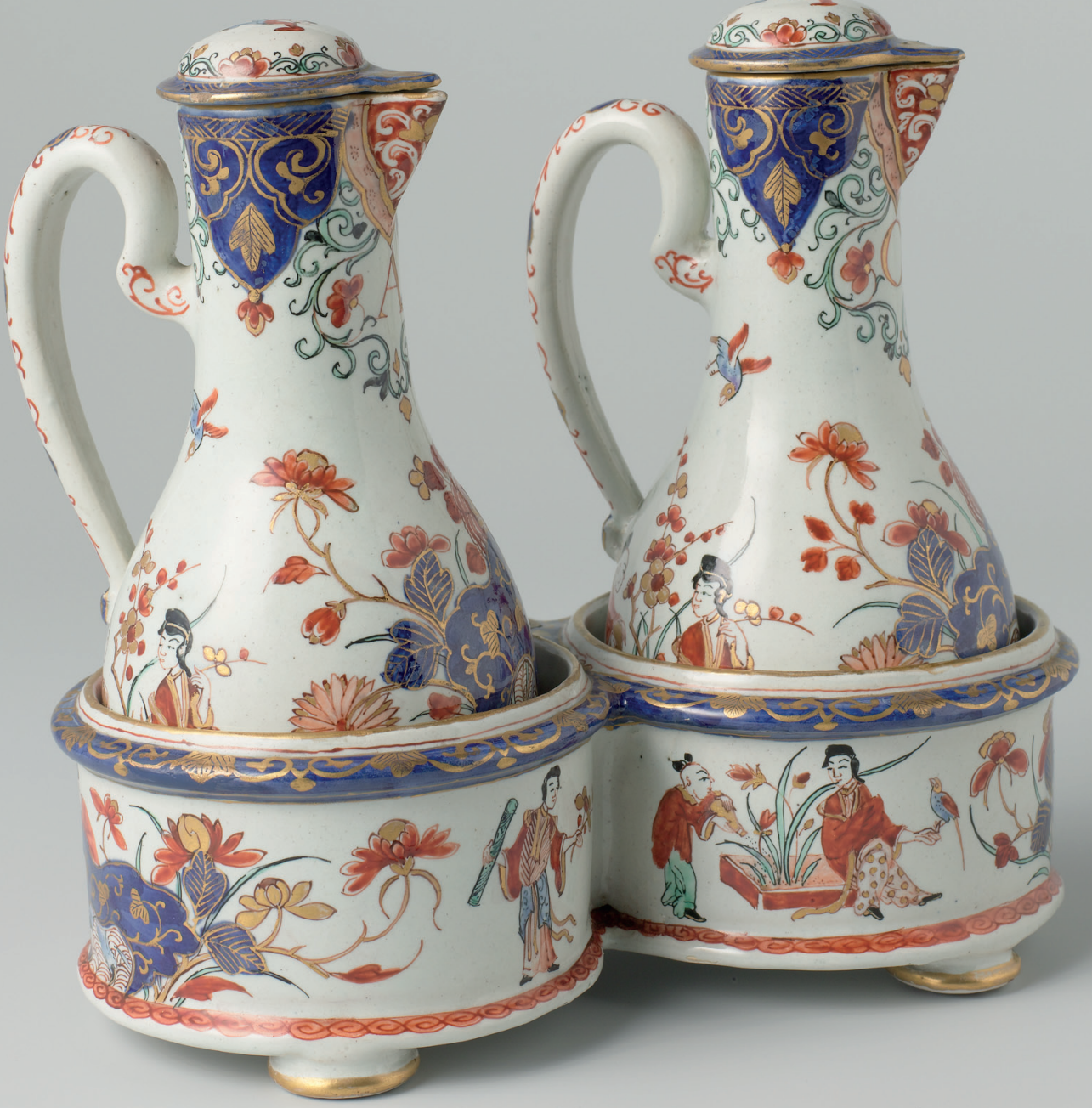

Afb. 2

Olie- en azijnstel bestaande uit een houder en twee kannen, geglazuurd aardewerk (faïence), Delft,

ca. 1705 - ca. 1725, Rijksmuseum Amsterdam, inv.nr. BK-NM-12400-331 


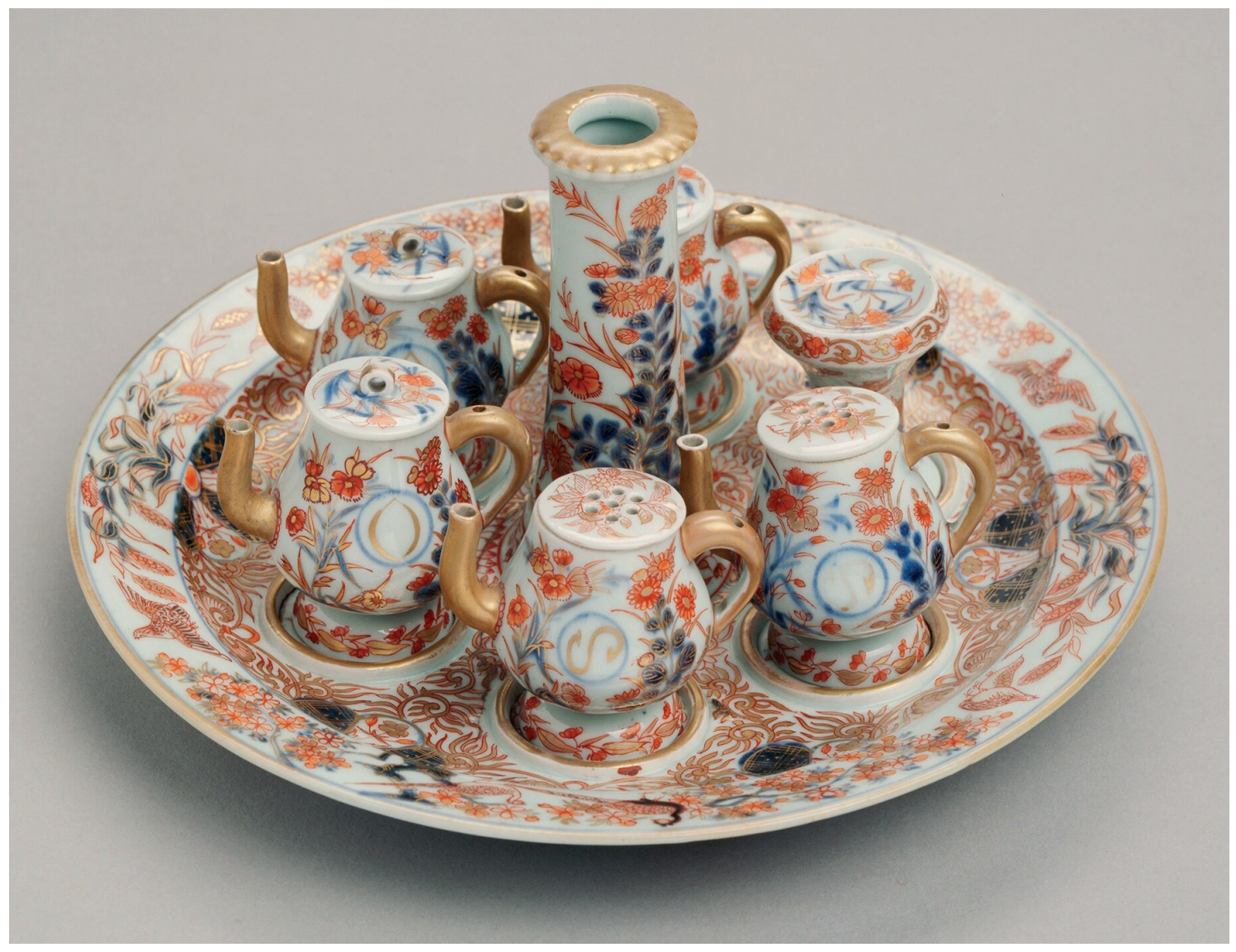

Afb. 3

Olie- en azijnset, Imari, versierd met onderglazuur blauw, ijzerrood en goud, plateau h. $14 \mathrm{~cm} . x$ diam. 29 cm.; kannetjes h. 7-7.4 cm.; zoutvat h. $6.5 \mathrm{~cm}$., Japan, $1^{\mathrm{e}}$ kwart $18^{\mathrm{e}}$ eeuw, Jan Menze van Diepen Stichting, inv.nr. JMD-P-2456 populairste teksten is zijn Geestige en vermaecklycke reijsbeschrijving naar Oost-Indiën, oorspronkelijk gepubliceerd in Amsterdam in 1669, gebaseerd op twee brieven vol schuine grappen, erotische anekdotes, en beschrijvingen van het dagelijkse leven aan boord. ${ }^{5}$

In Batavia schreef hij natuurlijk ook, onder andere een gedicht voor een jong meisje, 'mejuffrou N.N. Op haer Eeds. Sevenste Verjaren, Ao. 1669'. ${ }^{6} \mathrm{Hij}$ beschrijft haar als 'Kleine Juffer, groot van waerde/Schoonste vreugd, die ooit de Aerde/Heeft op Java voort gebracht'. Het gedicht is zijn geschenk voor het meisje:

Wenschen? wel gy hebt het al;

Rijkdom, aengename Schoonheyt,

Deugt, die in u klaer ten toon leyt;

Ook gezontheit en Verstand:

d' Eerste Dochter van het Land,

Dat de Leeuw met zeven Pijlen

Heeft gebouwt op vaste Stijlen?

Daer het al te warme Oost

Met haer Oegst den Koopman troost.

Valt 'er dan wat meer te wenschen

Gy gelukkigste der menschen? ${ }^{7}$ 


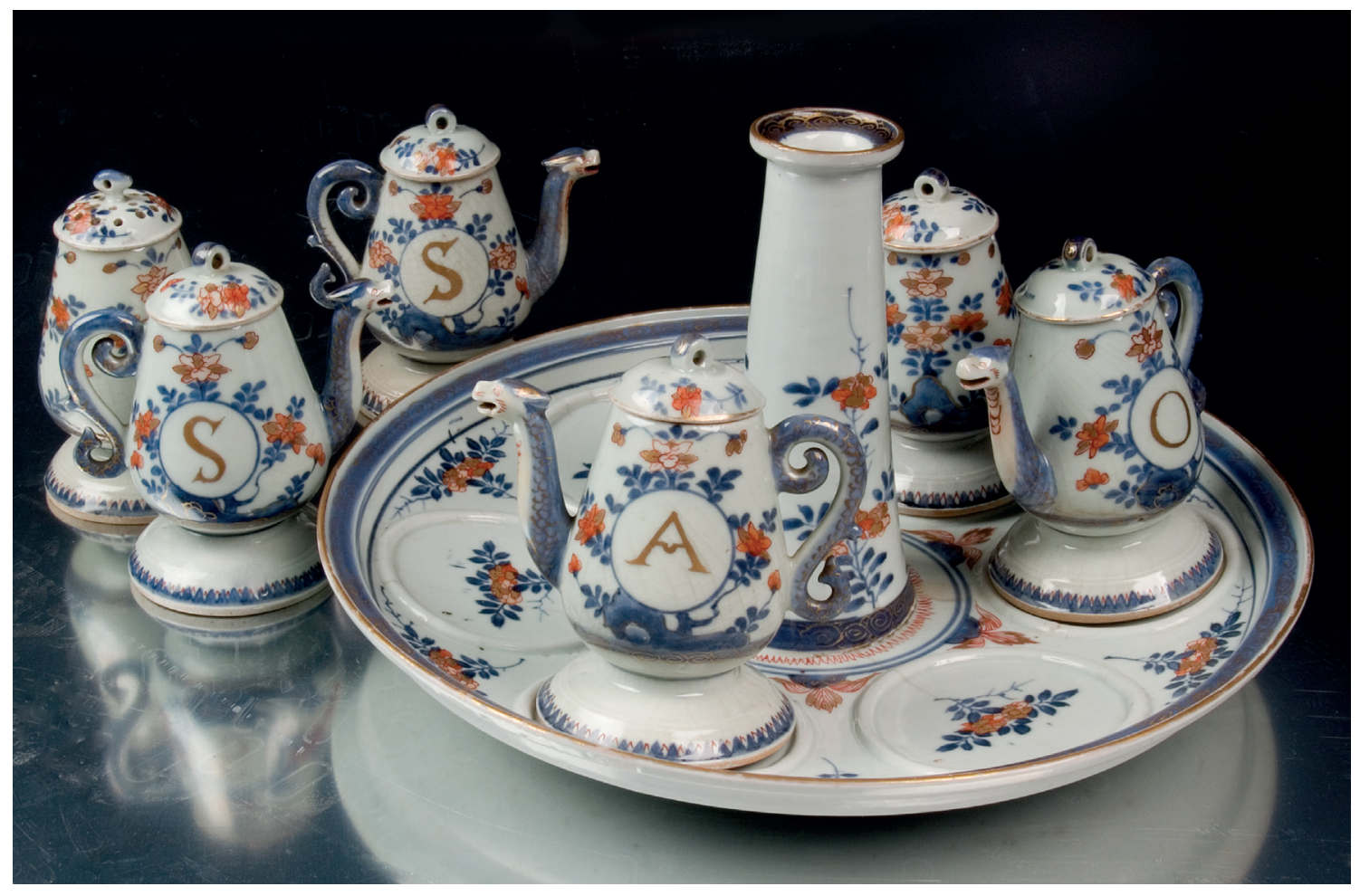

Afb. 4

Olie- en azijnstel, Imari porselein, onderschotel h. $20,5 \mathrm{~cm} x$ diam. $30,5 \mathrm{~cm}$., kannetjes h. $11,5 \mathrm{~cm}$., Japan, 17001720, Het Princessehof, inv.nr. LY 0599
Van Overbeke prijst het meisje, dat waarschijnlijk niet het eerste Nederlandse kind was dat in Batavia werd geboren (de stad werd al in 1619 door de VOC gevestigd); zij was een hooggeboren kind. Maar hij looft ook zijn omgeving, die ondanks de hitte veel te bieden heeft, niet alleen in de zin van winst uit de handel maar ook een aangename levensstijl. Zo beschrijft hij in hetzelfde gedicht een van de maaltijden die hij daar genoot:

Dat 's de saus die moet'er zijn:

Soya, gengber, loock en ritsjes,

Maeckt de maeg wel scharp en spitsjes:

Maer 't sijn viertjes, die men stoockt

Voor een pot die weynig koockt. ${ }^{8}$
Afb. 5

Een set van twee flesjes, porselein, beiden met een cirkelvormig medaillon respectievelijk de letter ' $A$ ' voor Azijn (inv.no. EA1978.423) en ' $S$ ' (in spiegelbeeld) voor Soya (inv.no. EA1978.424), Imari, Japan, ca. 1700, Ashmolean Museum

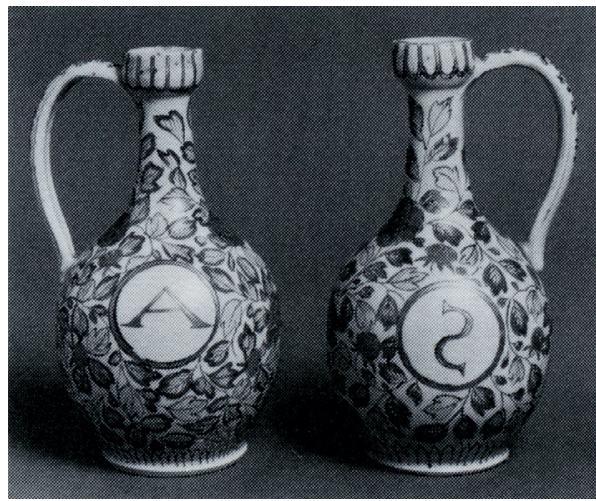


Afb. 6

Aernout van Overbeke (1632-74), door Jan Maurits Quinkhard, 1732-71, olieverf op koper, $11 \times 9,5$ cm., Rijksmuseum Amsterdam, inv.nr. SK-A-4607

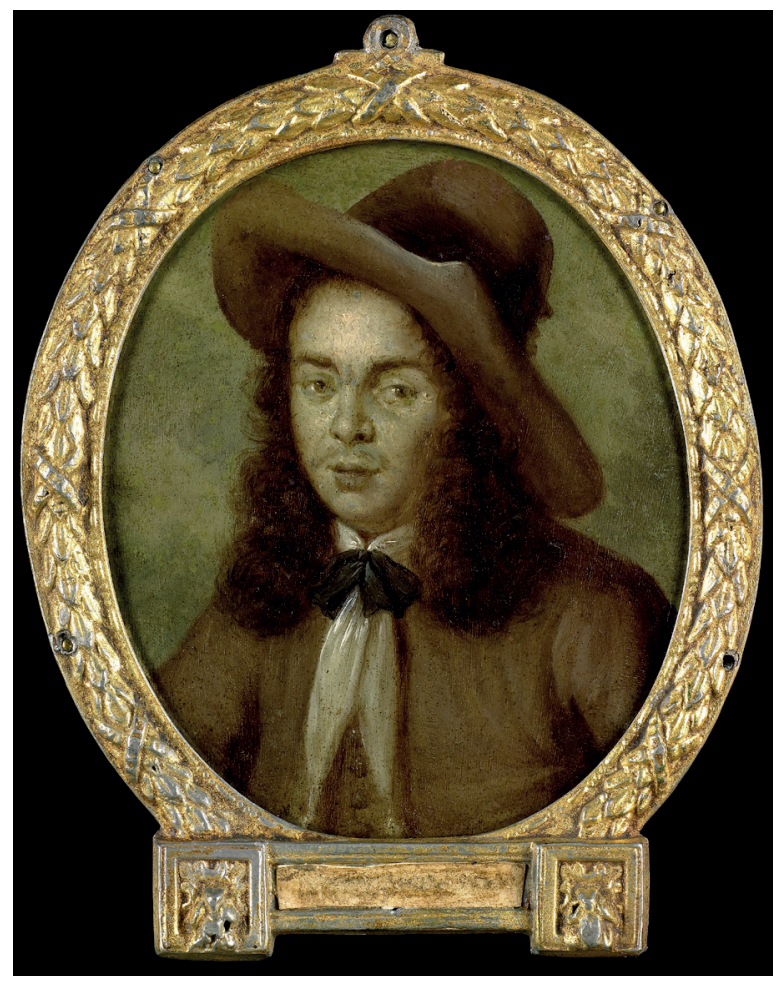

Een pittig sausje van soja, gember, ui en peper, wel wat scherp voor de maag, maar niet te versmaden. Het zijn ingrediënten die wij nu goed kennen uit de Aziatische keuken, maar die in de late $17^{\mathrm{e}}$ eeuw in Nederland nog weinig bekend waren. ${ }^{9}$ Dit gedicht van Van Overbeke is in ieder geval voor zover wij weten, de eerste schriftelijke Nederlandstalige vermelding van het gebruik van sojasaus.

Het is niet bekend of Van Overbeke wist dat de VOC al meer dan dertig jaar sojasaus verhandelde. De VOC zond al vanaf 1637 sojasaus van Batavia naar de handelshavens van Cambodja, Siam, Tonkin, en Formosa, en vanaf 1737 verschijnen zogenaamde 'kelders' sojasaus op de lijst van goederen die de VOC naar Nederland verscheepte. ${ }^{10}$ Kelders (ook wel keldertjes) waren kisten met afdelingen of vakken waarin flessen overeind staand bewaard of vervoerd konden worden. In de periode van honderd jaar, tussen die eerste intra-Aziatische verscheping in 1637 en het begin van officiële VOC handel in sojasaus in 1737, kwamen Nederlanders in Azië met sojasaus in aanraking, en kwam de saus ook al via de privéhandel naar Nederland. ${ }^{11}$ Tussen 1739 en 1763 importeerde de VOC omstreeks 500 kelders sojasaus in Nederland, met een gemiddelde opbrengst per kelder van 26 gulden. ${ }^{12}$

Het waren de Nederlanders die als eersten sojasaus naar Europa haalden, en vanwege hun toegang tot de Japanse markt door de handelsfactorij Deshima in de baai van Nagasaki ook de Japanse sojasaus introduceerden die het hoogst aangeschreven stond op de Europese markt. Flessen met daarop de tekst 'Japanschzoya' (afb. 7), bekend van museale collecties en archeologische vondsten in Azië en Europa, bevestigen de populariteit van de door de Nederlanders uit Japan geïmporteerde şjad ded from Brill.come4/26/2023 02:58:23AM 
Afb. 7

Fles met tekst

'Japanschzoya' in onderglazuur-blauw, Hasami kilns, Japan, Edo period, ca. 1810-50, h. $20.3 \mathrm{~cm}$. x diam. $10.5 \mathrm{~cm}$., () Victoria and Albert Museum, inv.no. C.633-1920

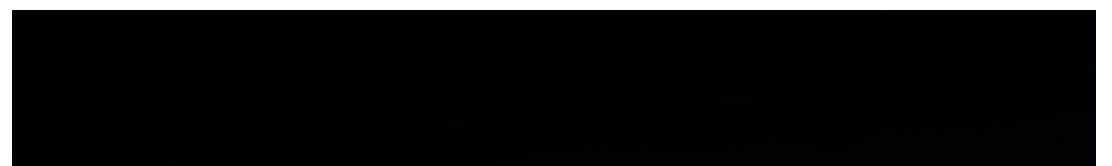

\section{De bereiding van sojasaus}

In de $18^{\mathrm{e}}$ eeuw raakte men in Nederland dus bekend met de uit Japan geïmporteerde sojasaus, zoals de olie- en azijnset uit afbeelding 3 ook al laat zien. De toepassing van sojasaus in de Nederlandse keuken vinden we terug in een van de bekendste kookboeken, uit 1746 (afb. 8). In het 'aanhangsel' van De volmaakte Hollandse keuken meid vinden wij onder het hoofdstuk 'Inleggen, Inzulten van Vleesch en Vis en veelerhanden Groenten voor de winter, als mede het toebereiden van eenige Tusschengeregten, Nageregten, Salade \&c.' de volgende tekst:

Soja, zo goed als die uit Oost-Indien komt, hoe men die maaken zal.

Neemt een dikke lende van een os of koe daar men al het vet in laat blyven, en zet het op 't vuur, daar by doende een goed deel zout en gestoote kruidnagelen:

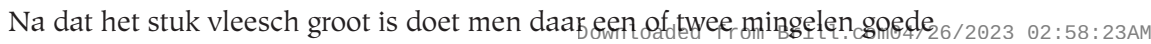


bronswyker Mom by, of anders van het beste bremer bier; van onderen moet men weinig, maar van boven veel vuur doen, en laat het zo lang staan tot dat al de sjeu uit het vleesch gebraden is, zo dat het van een valt; parst het uit, en giet dit vogt in een pan, laat het koud worden, dan komt er een dekzel van vet op dat men daar af ligt; en het overige wringt men door een schoone doek, en dan giet men het in flessen om te bewaaren.

Vooral de titel van dit korte hoofdstukje is intrigerend; de Hollandse huisvrouw kende dus niet alleen sojasaus, maar wilde in haar eigen keuken een saus kunnen maken die net 'zo goed' zou smaken 'als die uit Oost-Indien komt'. Het gaat hier duidelijk om een jus van rundvlees en bier, op smaak gemaakt met zout en kruidnagelen, en bewaard in flessen. Sojasaus uit 'OostIndien' werd heel anders gemaakt, namelijk van gefermenteerde sojabonen, gemengd met water en zout, en zal ongetwijfeld ook heel anders gesmaakt hebben dan de soja uit De volmaakte Hollandsche keuken meid, maar het is boeiend dat de standaard die men hoopte te bereiken met dit oer-Hollandse recept gelegd werd door de geïmporteerde Aziatische sojasaus. Juist in deze periode verspreidde zich de kennis over het maken van Aziatische sojasaus ook in Europa. De arts en bioloog Maarten Houttuyn (Hoorn, 1720-98) beschreef sojasaus in zijn boek Natuurlyke Historie of uitvoerige beschryving der dieren, planten en mineraalen, volgens het samenstel van Linnaeus onder het lemma Dolichos soja, ofwel de 'Japansche' sojaboon:

Men vindt wel verscheidene Soorten van dit Geslagt in Japan, doch deeze verdient den bynaam met het grootste regt, om dat 'er de Japansche soja van gemaakt wordt. Het is een Lymerig en niet onaangenaam ziltig Sap, dat in

Afb. 8

'Drie keukenmeiden aan het werk', gravure door F.J. Walther, titelpagina voor $\mathrm{De}$ volmaakte Hollandsche keuken meid, 1746, Rijksmuseum Amsterdam, inv.nr. RP-P-19381221

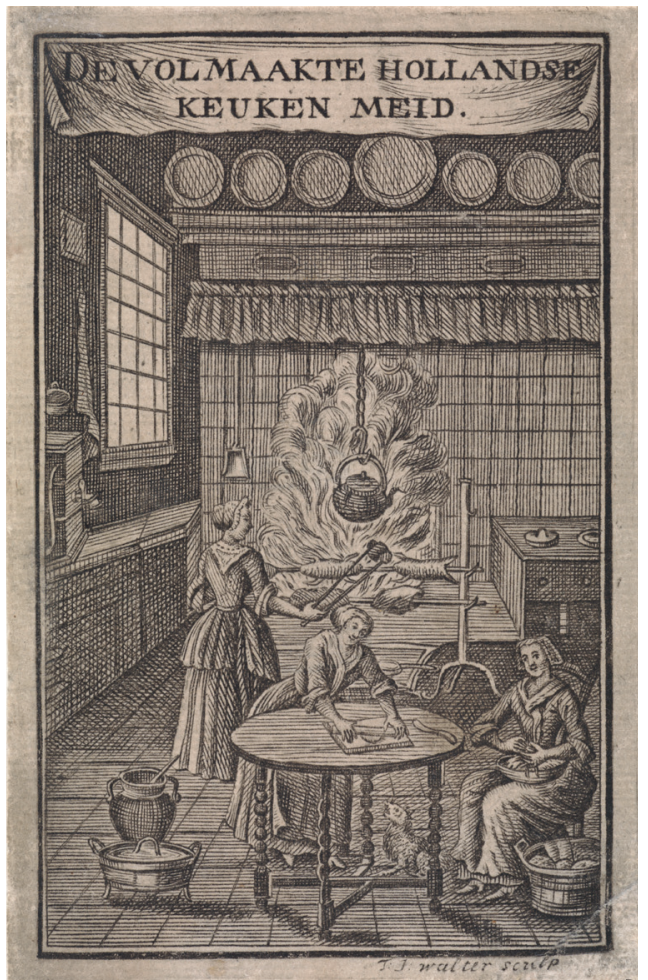


Fleschen overkomt, en, in plaats van Vleesch-Sap of Sjeu, over Erwten en andere Spyzen gegeten wordt, om den Appetyt te verwekken. In Oostindie is inzonderheid daar toe veel in gebruik, zo wel het Echte Japansche, als het nagemaakte Chineesche en ander van slegter hoedanigheid. ${ }^{13}$

Dit citaat laat nogmaals zien dat de sojasaus die in flessen uit Azië overkwam in Europa op een vergelijkbare manier werd gebruikt als vleesjus, en dat de Japanse saus als superieur werd gezien boven de Chinese. Het feit dat sojasaus veel eerder in China gemaakt werd dan in Japan, en dat de Japanse saus dus eigenlijk de 'nagemaakte' saus is, is kennelijk minder belangrijk. De Zweed Carl Gustaf Ekeberg sprak in 1764 de Zweedse Academie der Wetenschappen toe over het onderwerp van Chinese soja, en Isaac Titsingh (1745-1812) publiceerde in 1787 ook een korte verhandeling over de 'Bereiding van de soija'. ${ }^{14}$ De 18 eeuw was dus duidelijk de tijd van de globale handel in soja, de integratie in de Hollandse keuken, en de verbreiding van kennis over het maken van sojasaus.

\section{Tot slot}

Laten we nogmaals terugkeren naar de olie- en azijnset uit de Jan Menze van Diepenstichting. $\mathrm{Al}$ is de aanwezigheid van een kannetje voor het schenken van sojasaus nu beter verklaarbaar geworden, nog altijd roept de vroege datum (tussen 1700 en 1725) van dit object verwondering op. Als we aannemen dat dit plateau met zijn verschillende kannetjes in Japan op bestelling van de Nederlanders gemaakt is, dan gebeurde dit dus voordat de VOC officieel in sojasaus ging handelen. Het lijkt dan waarschijnlijk dat het speciaal gemaakt is voor een Nederlander die in Azië, Batavia of Deshima gewend was geraakt aan het gebruik van sojasaus als smaakversterker, en voor vertrek naar huis nog deze speciale bestelling plaatste. Het kleine aantal overgebleven exemplaren van dit soort pronkstukken maakt dit aannemelijk. Complete sets, waarbij alle potjes, kannetjes en zoutvaatjes nog aanwezig zijn, zijn zeldzaam. Natuurlijk was dit deels het gevolg van de vele breekbare losse stukken waaruit deze setjes bestonden; de kans dat een dekseltje of tuitje beschadigd werd tijdens transport of gebruik was zonder meer groot. Deze complete setjes zijn duidelijk met veel zorg samengesteld, vervoerd, en bewaard. Ook dat duidt op speciale bestellingen voor hoge VOC ambtenaren en machtige en belangrijke kenners zoals Augustus de Sterke. Vanaf het midden van de $18^{\mathrm{e}}$ eeuw werd sojasaus veelvuldig gebruikt en nagemaakt door de huisvrouwen en koks die De volmaakte Hollandse keuken meid lazen; het was met andere woorden niet langer een elitair product. Door kennis van materiële kunst in de uitwisselingen tussen Azië en Europa te combineren met kennis van de eetcultuur kunnen we meer zeggen over objecten als de olie- en azijnset uit de Van Diepen collectie.

- Anne Gerritsen is Associate Professor in de Chinese geschiedenis aan de Universiteit van Warwick (Engeland). Zij heeft in Leiden Chinees gestudeerd, en is gepromoveerd op de universiteit van Harvard. Recentelijk richt ze haar onderzoek op de materiële cultuur van China, met name porselein, en op de plaatselijke en globale geschiedenis van het produceren van porselein in Jingdezhen (China). Tussen 2013 en 2018 bekleedt zij de Kikkoman Chair for the Study of Asia-Europe Intercultural Dynamics aan de Universiteit Leiden. 


\section{Literatuur}

Donna R. Barnes en Ruud Spruit, Food for Thought, Peter Sasburg, Midwoud, 2010.

Carl Gustaf Ekeberg, 'Om Chineska Soyan', Stockholm, 1764. [rede]

Maarten Houttuyn, Natuurlyke Historie of uitvoerige beschryving der dieren, planten en mineraalen, volgens het samenstel van Linnaeus, Amsterdam, 1761-1785.

Engelbert Kaempfer en Detlef Haberland, Briefe, 1683-1715, Iudicium, München, 2001.

Christiaan J. A. Jörg, Jan Menze van Diepen Stichting: Een Selectie uit de Collectie Oosterse Keramiek, Jan Menze van Diepen Stichting, Slochteren, 2002.

Jan Willem Claus van Laar, De volmaakte Hollandsche keuken meid en Aanhangzel van de volmaakte Hollandsche keuken-meid. Steven van Esveldt, Amsterdam, 1754. [derde druk.]

M. Lindbom, 'Method of preparing the Chinese soy by M. de Grubbens: extracted from the memoirs of the academy of sciences at Stockholm for 1803, first quarter, Philosophical Magazine Series 1, 19/75 (1803): 260-3.

Chris Nierstrasz, Rivalry for Trade in Tea and Textiles: The English and Dutch East India Companies (1700-1800), Palgrave, Basingstoke, te verschijnen.

Aernout van Overbeke, Geestige en vermaeckelijcke reys-beschryving naer Oost-Indien, Utrecht, 1994 [red. Werkgroep van Utrechtse neerlandici, Oorspr. uitg. 1669].

Aernout van Overbeke, De rymwercken (red. Jan Claesz ten Hoorn), Jan ten Hoorn, Amsterdam, 1709 [negende druk.]

Friedrich Reichel en Jürgen Karpinski, Altjapanisches Porzellan aus Arita in der Dresdener Porzellansammlung, Ed. Popp, Würzburg, 1980.

William Shurtleff, H.T. Huang, en Akiko Aoyagi, History of Soybeans and Soyfoods in China and Taiwan, Soyinfo Center, 2014. Zie: http://www.soyinfocenter.com/pdf/176/ Chin.pdf

Isaac Titsingh, 'Bereiding van de soija', Verhandelingen van het BataviaaschGenootschap van Kunsten en Wetenschappen 3 (1787), pp. 245-6.

Cynthia Viallé, 'Japanese Products Exported to Asia and Europe in the Edo Period', in: Frederik Cryns and Fuyuko Matsukata (red.), Nichirankankeishi wo yomitoku [Revisiting the History of Dutch-Japanese relations], Kyoto: Rinsen Shoten, te verschijnen 2015 .

\section{Noten}

1. De collecties van de Jan Menze van Diepenstichting zijn ondergebracht in de Fraeylemaborg in Slochteren. De collectie is ook online: http://www. vandiepencollectie.nl/nl/.

2. Jörg 2002: 198-9.

3. Reichel 1980, cat. 59, geciteerd in Jörg 2002: 198.

4. Set van vier miniaturen, Imari, Japan, 1690-1720, Groninger Museum, mosterdpotje inv.nr. 1945-509, po inv.nr. 1945-665., kwispedoor inv.nr. 1990-429, zoutvat inv.nr. 1955-311.

5. Van Overbeke 1994 [1669].

6. Van Overbeke 1709: 73.

7. Van Overbeke 1709: 78.

8. Van Overbeke 1709: 74.

9. Barnes 2010: 75-84.

10. Viallé 2015; Shurtleff 2014: 10.

11. Engelbert Kaempfer $(1651-1716)$ vermeldt bijvoorbeeld in een brief gedateerd 26 november 1693 dat hij sojasaus als cadeau stuurt aan Jan Parvé (1643-1697), die in Batavia werkte tot hij in 1689 naar Amsterdam terugkeerde. Zie E. Kaempfer, Briefe 1683-1715, Band 2: 432, regel 43 noot.

12. Deze hoeveelheden en bedragen zijn gebaseerd op lopend onderzoek door de historicus Chris Nierstrasz. Zie ook Nierstrasz, te verschijnen.

13. Houttuyn 1761-1785: Volume II, part 10: 158.

14. Ekeberg 1764; Lindbom 1803; Titsing 1787: 245 r6.loaded from Brill.com04/26/2023 02:58:23AM 
Afb. 1

Kom, opaak wit en groen glas, China, $19^{e}$ eeuw, h. $4,8 \mathrm{~cm}$., d. 8,3 cm., Rijksmuseum Amsterdam, inv.nr. BK-18956. Legaat van L.E.C. Verkouteren. Foto: Rijksmuseum Amsterdam

Afb. 2

Zijaanzicht met dierenmasker van groen glas. Foto: Rijksmuseum

Amsterdam

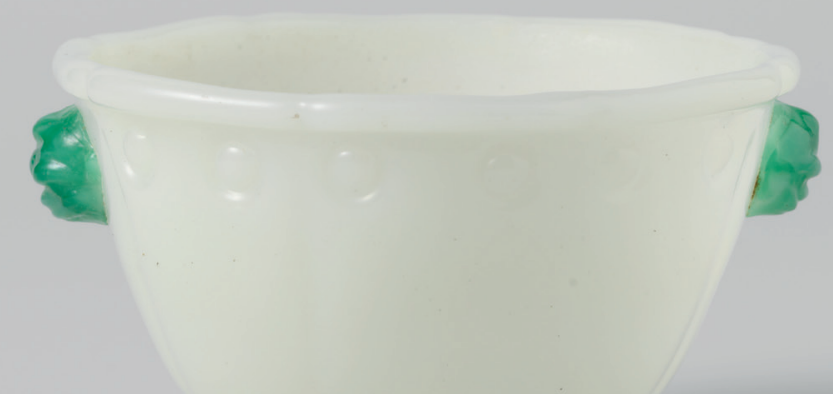

